\title{
PS.- ESCÍLAX § 20, LA DESCRIPCIÓN DEL DANUBIO Y EL PROBLEMA DE LAS FUENTES DEL PERIPLO
}

If the conjecture generally admitted for Ps.Scylax $\S 20$ is accepted, then the author of this Periplus agrees with Herodotus' description of the Danube river. However, the mention of Danube's Adriatic mouth takes up a different tradition, first documented in Theopompus. This discrepancy asks for a throughout discussion of Ps.Scylax' sources.

Si el Periplo del Ps.-Escílax es una de las obras que dentro de su género ha suscitado más la atención de los filólogos, empeñados en hallar la solución definitiva al intrincado problema de su autoría y en brindar una interpretación satisfactoria a todas y cada una de las cuestiones que encierra su contenido, no es menos cierto que más de un pasaje sigue reclamando hoy en día una revisión. A ello han contribuido, sin duda, las propias deficiencias de un texto que reclama a voces una edición moderna'.

Uno de los pasajes que ha levantado no poca polémica durante centurias es precisamente el que ofrecemos como materia de estudio en el presente trabajo, y que a continuación reproducimos:

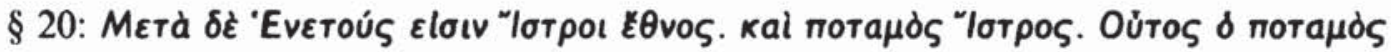

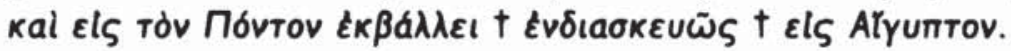

Después de los Vénetos viene el pueblo de los Istros y el río Danubio. Este río desemboca también en el Ponto, $\dagger$ orientado como $t$ en dirección a Egipto.

La crítica especializada no ha escatimado esfuerzos en dar una ex-

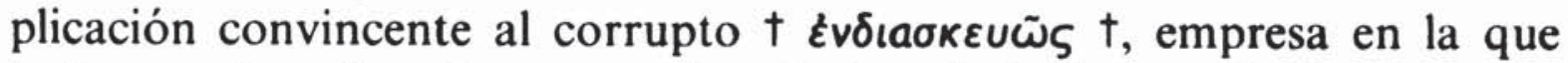
incluso se han llegado a rozar los limites de la fantasía ${ }^{2}$. En resumen,

' Sobre el texto manuscrito y las ediciones disponibles cf. F. J. González Ponce, Avieno y el Periplo, Ecija, Ed. Gráficas Sol, p. 64, nn. 26 y 28.

${ }^{2}$ El propio C. Müller, Geographi Graeci Minores, París 1855, vol. I, p. 26, n., tras comentar cada una de las interpretaciones, viene a refrendar nuestra opinión en términos bien reveladores: "sed vereor ne nugemur", de cuyo parecer se hace eco A. Peretti, «Teopompo e Pseudo-Scilace», $S C O$ 12, 1963, p. 66, n. 118. 
todas las conjeturas propuestas quedan agrupadas en torno a dos ideas principales. En opinión de unos dicha expresión hace referencia a la desembocadura del río, en forma de delta, como la del Nilo en Egipto. Así,

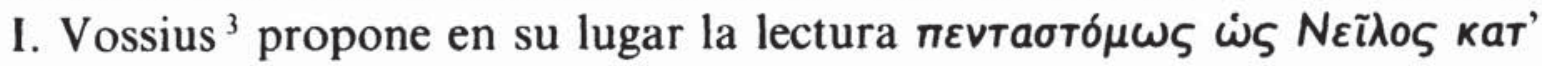

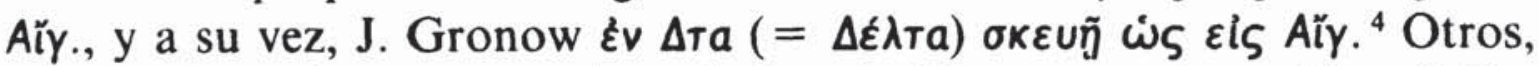
en cambio, opinan que aquí se alude más bien a su orientación: el Danubio, según el autor, miraría hacia el Sur, justo hacia Egipto. Así lo entiende L. Holsten ${ }^{5}$, que traduce el lugar "exit fluvius ad Pontum, fronte quasi in Aegyptum conversa». Siguiendo a Holsten, J. F. Gail ${ }^{6}$

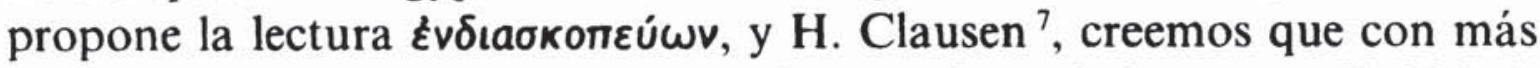

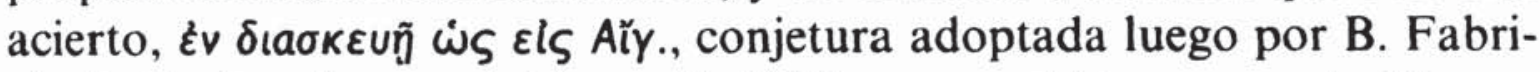
cius $^{8}$. De la misma opinión es $C$. Müller, que, si bien no se decide por ninguna lectura en concreto, traduce el pasaje «spectans Aegyptum versus" ${ }^{9}$. Por último, partidario de la orientación es también, aunque con ciertas reservas, A. Peretti ${ }^{10}$.

A la vista de lo que acabamos de exponer podemos preguntarnos cuál de estas dos interpretaciones debe ser merecedora de un mayor grado de credibilidad - si es que alguno lo merece-; o lo que es lo mismo: si existen argumentos objetivos sobre los que fundamentar una y otra propuesta.

Dado que en la actualidad se han logrado notables progresos en lo referente a la autoría del Periplo y la fecha de su composición ${ }^{11}$, no resultan ya operativos los argumentos empleados por Gail, que se inclina

${ }^{3}$ Cf. I. Vossius, Periplus Scylacis Caryandensis cum translatione et castigationibus, Amsterdam 1639.

4 Es decir, «in literae Deltae habitu, prout contigit ad Aegyptum», según las propias palabras del autor. Cf. J. Gronow, Geographica antiqua [...], Lyon 1697 y 1700.

${ }_{5}$ Cf. J. F. Boissonade, Lucae Holstensii epistolae ad diversos [...], París 1817. La relación de los escritos de L. Holsten (1596-1661) puede verse en A. Diller, The Tradition of the Minor Greek Geographers, Oxford-Lancaster 1952, pp. 54-58.

${ }^{6}$ Cf. J. G. Gail, Dissertation sur le périple de Scylax et sur l'époque présumée de sa rédaction, París 1825 .

7 Cf. H. Clausen, Hecataeii Milesii fragmenta et Scylacis Caryandensis periplus, Berlin 1831.

${ }_{8}$ Tanto en su edición de 1878 (B. Fabricius, Anonymi, vulgo Scylacis Caryandensis, periplum maris interni cum appendice iterum, Leipzig 1878), como en Scylacis periplus ex recensione $B$. Fabricii, Dresde 1848 .

${ }_{9}$ Müller, op. cit. en n. 2, ibidem, mantiene en el cuerpo de texto la lectura del

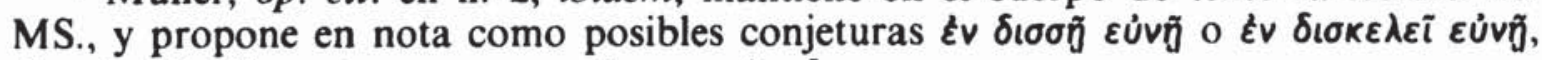

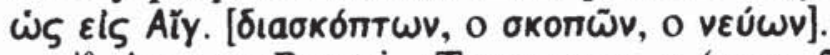

10 Aunque Peretti, "Teopompo...» (en n. 2), p. 66, se limita sólo a advertir la incomprensibilidad del pasaje, parece inclinarse más bien por esta interpretación: «il confronto dell'Egitto con la foce dell'Istro [...] mi pare suggerito da Herodoto II 34-35, che paragona il corso dell'Istro con quello del Nilo" (la cursiva es nuestra).

"Una puesta al día sobre estas cuestiones se ofrece en González Ponce, op. cit. en n. 1 , p. 65 , n. 31 . 
por la segunda de las interpretaciones basándose en criterios cronológi$\cos ^{12}$. Ahora bien, lo que sí debe constituir un argumento de peso en la defensa de dicha conjetura es el paralelismo existente entre el citado pasaje del Periplo y lo que leemos en Heródoto II 34, como han subrayado ya otros autores. Que tanto Heródoto como Ps.-Escílax se están referiendo en sendos lugares a una misma realidad es un hecho indudable si completamos las escasas e inciertas palabras de $\S 20$ con lo que el mismo periplógrafo añade en $\S 102$ al hablar del trayecto interior desde Sinope hasta Cilicia a través del Asia Menor:

HERÓDOTO II 34

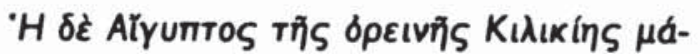

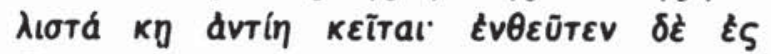

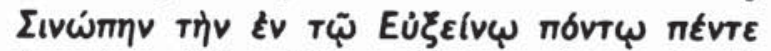

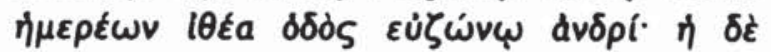

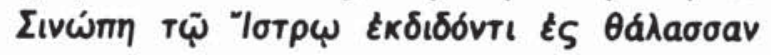
àtíov кEITtal.

Ahora bien. Egipto está poco más o menos enfrente de la montañosa Cilicia. Desde alli hasta Sinope, en el Ponto Euxino, hay en línea recta cinco días de camino para un viajero sin bagajes; $y$, por su parte, Sinope se halla frente a la desembocadura del Istro en el mar. ${ }^{13}$
PS.-ESCILAX $\S 102$

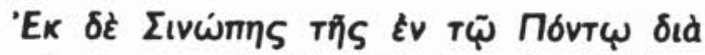

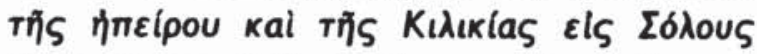

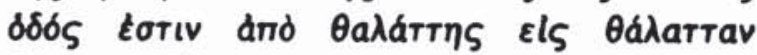

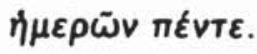

Desde Sinope en el Ponto hasta Solos el trayecto por tierra de costa a costa a través del continente y de Cilicia es de cinco días.

El paralelismo existente entre ambos pasajes es evidente, como demuestran las no pocas reminiscencias verbales. Sin embargo, se nos plantea ahora otra cuestión no menos importante: si dicho paralelismo debe hacernos pensar, exclusivamente, en un simple préstamo de Heródoto a nuestro autor, como mantiene la mayoría de los autores que se inclinan por ver en este pasaje una alusión a la orientación sur de la desembocadura del Danubio, incluso Peretti. Si prescindimos del contexto no parece haber motivo alguno para pensar lo contrario; no obstante basta tan sólo con una simple ojeada al resto de Periplo $\S 20$ para alber-

12 Gail, ap. Müller, op. cit. en n. 2, ibidem, que considera a nuestro Escílax contemporáneo de Heródoto, se opone a aquellos que ven en este pasaje una alusión al delta del Danubio basándose en el hecho de que la mención de tal delta sólo se da en autores posteriores a dicha fecha; por tanto, Escílax se referiría aquí no a la desembocadura, sino a la orientación del río, en plena consonancia con el historiador de Halicarnaso (II 32-34), coetáneo suyo. Ya el propio Müller desautorizó el citado razonamiento («aetas Scylacis non amplius impedimento est»).

13 Traducción de C. Schrader, Heródoto. Historias. Libros I-II, Madrid 1977. Heródoto expone el mismo parecer en I 72. 
gar serias dudas al respecto. En efecto, con la expresión $\mu \varepsilon т \dot{a} ~ \delta \varepsilon \dot{~ ' E v \varepsilon-~}$

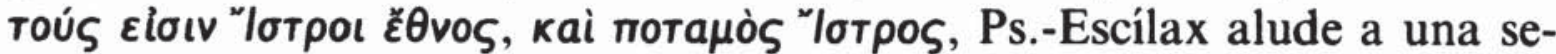
gunda desembocadura del Danubio: su boca adriática, y por tanto se aparta de Heródoto, que en II 33 nos describe dicho río como paralelo al Nilo, con una sola desembocadura (en el Ponto Euxino) y procedente, igual que este último, de Occidente (el Danubio desde el Occidente europeo, el Nilo desde el líbico):

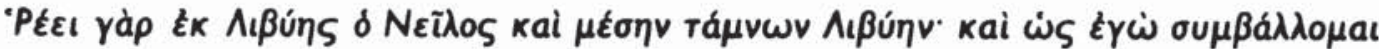

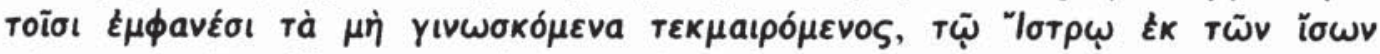

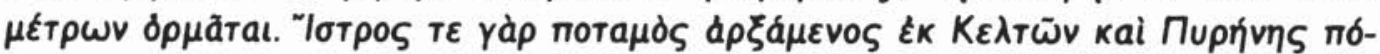

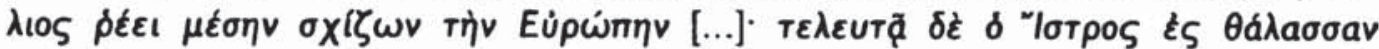

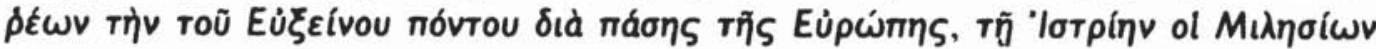
olkéouoı ănoıkoı.
\end{abstract}

En efecto, el Nilo procede de Libia y la divide por la mitad; además, en la medida en que, por meros indicios, puedo presuponer lo que se desconoce a partir de lo que es manifiesto, tiene su origen a una distancia similar a la del Istro. Este río, como es sabido, comienza en la ciudad de Pirene, en el país de los Celtas y, en su curso, divide Europa por la mitad [...]. El Istro, pues, atraviesa toda Europa y su curso termina en el mar del Ponto Euxino, en los aledaños de Istria, ciudad que habitan colonos de Mileto ${ }^{14}$.

Al aceptar la desembocadura adriática del Danubio Ps.-Escílax, por tanto, pasa a formar parte de toda una tradición diversa. Y si la mención de dicha boca está atestiguada por primera vez en Teopompo ${ }^{15}$, todo hace suponer que, al menos en esta concepción, Ps.-Escílax es deudor del historiógrafo de Quíos, como mantienen sin más los partidarios de la teoría tradicional ${ }^{16}$.

Así pues, llegados a este punto nos encontramos ante una cuestión fundamental que requiere respuesta satisfactoria: según lo que leemos en $\S 20$, ¿cuál habría sido el modelo seguido por Ps.-Escílax en su concepción del curso del Danubio, Heródoto o Teopompo? Si parece descartarse el seguimiento de un solo autor, ¿cabe pensar que el periplógrafo haya seguido en la descripción de un mismo motivo geográfico a dos modelos cuya información es contradictoria? O lo que encaja más directamente con el propósito de nuestro trabajo: ¿la mención de la boca adriática del Danubio puede representar un obstáculo para la defensa de la conjetura por la que nos hemos inclinado basándonos en el para-

14 Traducción de Schrader, op. cit. en n. 13. Una descripción similar del río puede verse en IV 48-50 y 99.

is Cf. FGrHist. 115 F 129 (= Estrabón VII 5, 9).

16 Sobre este punto cf. Peretti, «Teopompo...» (en n. 2), pp. 16-22. 
lelismo con Heródoto? Dicha respuesta requiere, una vez más, el replanteamiento del manido problema de las fuentes del Ps.-Escílax.

Desde el punto de vista de la Geografia antigua la concepción del río que ofrece cada uno de los posibles modelos del Periplo responde a presupuestos bien distintos. Ante la imposibilidad de contar en este caso con testimonios empíricos, Heródoto se basa para la descripción del Danubio exclusivamente en deducciones teóricas, como él mismo re-

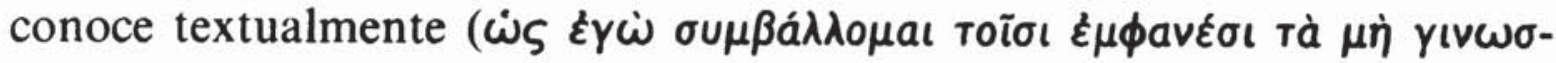

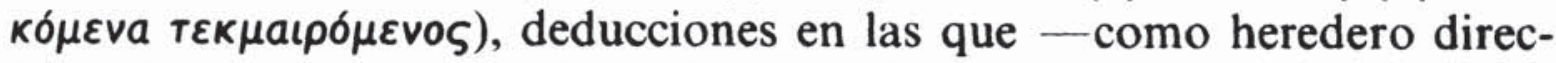
to de los primeros pensadores jonios - hace gala del que puede considerarse principio imperante en su concepción del escenario geográfico de la ecúmene: nos estamos refiriendo a la analogía comparativa, a la simetría geográfica, que da como resultado una visión geométrica del mundo a base de unidades rectangulares ${ }^{17}$.

Frentre a Heródoto, la mención por parte de Teopompo de una boca adriática del río no es el resultado de ningún tipo de especulación teórica. Es más, ni siquiera debemos considerar a Teopompo como el punto de partida del citado «error». Según apunta Peretti muy acertadamente ${ }^{18}$, el proceso de comprensión de esta concepción geográfica empieza a cobrar nuevas luces si tenemos en cuenta primero que el seno del Adriático fue escenario, al menos desde finales del siglo vi a. C., de una importante presencia griega: colonias griegas como Espina y Adria mantuvieron un intenso comercio con los Etruscos, sobre todo a raíz del cierre del Estrecho por parte de los Cartagineses. Si además se considera la existencia en dicha zona de reminiscencias toponomásticas mitológicas como Apsírtides (islas) $\leftrightarrow$ Apsirto (hijo de Eetes), y se establecen ecuaciones como Istros (habitantes de la costa adriática) $\leftrightarrow$ Istros $\rightleftarrows$ Istria

${ }_{17}$ El principio de simetría aplicado a la concepción geográfica del mundo es una constante en la obra de los geógrafos antiguos, ya desde los primeros físicos, diseñadores de la Carta Jonia. En Heródoto dicho principio impera a veces sobre la exactitud de los datos geográficos que él mismo facilita, como ocurre en el caso de Escitia, que en IV 101 nos es descrita como un cuadrilátero de lados equidistantes. En el caso del Danubio, las deducciones analógicas de Heródoto debieron tener cierto éxito, llegando a ser aceptadas en épocas posteriores incluso por Aristóteles, que en Mete. I 13, vuelve a defender el origen pirenaico del río. Sobre estas cuestiones cf. E. H. Bunbury, History of Ancient Geography, Londres 1879, vol. I, pp. 167-172 y 181; F. Jacoby, FGrHist. 1 F 289 (y comentario); J. O. Thomson, History of Ancient Geography, Cambridge 1948, p. 98; J. L. Myres, Herodotus, Father of History, Oxford 1953, pp. 32-46; Ph. E. Legrand (ed.), Hérodote. Histoires. Livre II, Paris 1963 [1930], p. 88; Schrader, op. cit. en n. 13, pp. 316-317, y Libros III-IV, Madrid 1979, p. 383; y W. W. How y J. Wells, A Commentary on Herodotus, Oxford 1989 [1912], vol. I, pp. 178, 424-429 y 434-437.

${ }_{18}$ Cf. Peretti, «Teopompo...» (en n. 2), pp. 67-70. 
(pueblo y ciudad del Ponto, en la verdadera boca), reforzada por la homonimia de ambos con el nombre del río, se entiende fácilmente que el extremo del Adriático - el ángulo más remoto de Grecia - quedase ligado desde muy pronto a la saga legendaria de los Argonautas. Detrás de la idea de la bifurcación del Danubio afloran, por tanto, las propias .exigencias legendarias aludidas, a las que dan pie la ausencia de un verdadero conocimiento autóptico del curso medio y alto del río ${ }^{19}$.

A su vez, el relato de la boca adriática está íntimamente ligado a otra concepción del río justificada también en el seno de la propia leyenda: la de aquellos autores que defienden su origen nórdico. Dicha concepción, de la que Heródoto parece no haber tenido noticias, es antigua, y se remonta a una vieja tradición de la geografia jonia en virtud de la cual se localizaba las fuentes del Danubio en los montes Ripeos, en territorio de los Hiperbóreos ${ }^{20}$. Tal parecer se lee ya en Alcmán, Damastes y Esquilo ${ }^{21}$. La simbiosis de ambas concepciones (origen nórdico y desembocadura en el Adriático) puede comprobarse en Apolonio de Rodas ${ }^{22}$. A pesar de su origen mitológico y puramente circunstancial, esta figuración geográfica del Danubio contó con una larga lista de partidarios en la antigüedad ${ }^{23}$. Además de los citados, la misma idea era ya compartida por Hiponacte, y se lee de nuevo, entre otros, en Aristóteles, Ps.-Aristóteles, Timágeto, probablemente en Timonacte, y en Calímaco; y a pesar de que la creencia fue rebatida por Eratóstenes, sigue siendo defendida por Hiparco, Ps.-Escimno y Antípatro de Tesalónica ${ }^{24}$. En contra de dicho parecer se manifiestan abiertamente

${ }^{19}$ A pesar de que en dicha región no haya ningún río que por su tamaño o importancia hubiera podido sugerir su equiparación con el Danubio (los nombres propuestos son meros riachuelos), dicha concepción fue, sin embargo, un cómodo recurso para la explicación del paso de los Argonautas y de su salida al mar por aquellos lugares. Sobre esta cuestión cf. G. S. Shrimpton, Theopompus the Historian, McGillQueen 1991, pp. 94-101.

${ }^{20}$ Cf. E. Livrea (ed.), Argonauticon liber quartus, Florencia 1973, p. 97, n. a v. 287.

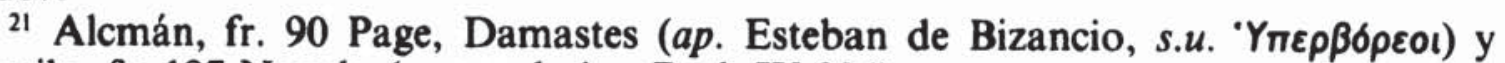
Esquilo, fr. 197 Nauck $_{2}$ (= escol. Ap. Rod. IV 284).

${ }^{22}$ Apolonio de Rodas IV 284 ss., 302, 309, 325. Cf. a este respecto la imagen del Danubio bifurcado que presenta F. Vian (ed.), Apollonios de Rhodes. Argonautiques. Tome III (Chant IV), París 1981, mapa III.

${ }^{23}$ Cf. Müller, op. cit. en n. 2, ibidem; Bunbury, op. cit. en n. 17, vol. I, pp. 384389; Thomson, op. cit. en n. 17, pp. 48, 141, 197, 226 y 250; Peretti, "Teopompo..." (en n. 2), p. 67; G. Aujac y F. Lasserre (edd.), Strabon. Géographie. Tome I, París 1969 , p. 211, n. 7; Livrea op. cit. en n. 20, pp. 97 y 99 , nn. a vv. 287 y 290 , con abundante bibliografia; Vian, op. cit. en n. 22, pp. 17-18; M. Brioso (tr.), Apolonio de Rodas. Las Argonáuticas, Madrid 1986, pp. 184-185, n. 611, y S. Bianchetti, Plotá kai porentá, Roma 1990.

${ }^{24}$ Hiponacte, fr. 2 Masson (= escol. Ap. Rod. IV 321-322); Aristóteles, HA VIII 
Estrabón y Diodoro Sículo ${ }^{25}$, sin embargo, hay autores que siguen haciéndose eco de la antigua convicción, como Mela, Plinio, Dionisio el Periegeta, e incluso otros tan tardíos como Justino, Pisandro de Laranda y Olimpiodoro de Tebas, Zósimo, Sozómeno y Nicéforo de Calisto ${ }^{26}$.

Ni que decir tiene que la coexistencia en Ps.-Escílax $§ 20$ de dos tradiciones geográficas opuestas y de naturaleza tan diversa como hemos intentado poner de manifiesto constituye en sí misma un sólido argumento en el que basarse para proponer una respuesta negativa al primero de los interrogantes arriba planteados: el autor del Periplo, al menos en lo que se refiere a este pasaje, no debe ser considerado deudor directo ni de Heródoto ni de Teopompo, como daba por hecho la communis opinio. De lo contrario, la incongruencia es algo evidente.

La hipótesis de trabajo que acabamos de establecer en atención a la irreconciliable contradicción implícita en el contenido geográfico que ofrece el $\S 20$ del Periplo se ve curiosamente refrendada por las recientes y valiosas aportaciones de Peretti sobre la naturaleza de la obra en general y, en concreto, sobre el llevado y traído problema de sus fuentes.

$\mathrm{Si}$, como Peretti, entendemos que Ps.-Escílax, o más bien el modelo por él imitado, se remonta en último extremo a un cúmulo de «literatura” náutica, empírica y práctica, a una tradición ya varias veces secular de anotaciones marineras, de apuntes y manuales de a bordo realizados por pilotos y comerciantes, carentes de todo tipo de preocupación científica, si - según la terminología del propio autor italiano- en el seno de nuestra obra subyace un periplo preliterario, completado luego por un compilador anónimo a base de noticias recentiores ${ }^{27}$, el debate sobre las fuentes del Ps.-Escílax toma, sin duda, un nuevo rumbo.

En lo que se refiere a la afinidad de nuestra obra con Teopompo, las aportaciones de Peretti son suficientemente reveladoras. Según él, ninguna de las indudables analogías existentes entre ambas descripcio-

13; Ps.-Aristóteles, Mir. CV; Timágeto, escol. Ap. Rod. IV 257-262; Timonacte, FGrHist. 842 F 1 (= escol. Ap. Rod. IV 321-322); Calímaco, frs. 9-11 y 186, 8-9 Pfeiffer; Eratóstenes, ap. Estrabón I 3, 2; Hiparco, ap. Estrabón I 3, 15; Ps.-Escimno 193-195 y 771-774, y Antípatro de Tesalónica, AP IX 550, 4 (= Gow-Page XCIV 606).

25 Estrabón I 2, 39 y 3, 15 y Diodoro Sículo IV 56.

26 Mela II 8 y 57; Plinio, Nat. III 128; Dionisio el Periegeta 315 ss.; Justino XXXII 3, 13-15; Pisandro de Laranda y Olimpiodoro de Tebas (ap. sequ.); Zósimo V 29, 2-3; Sozómeno I 6, 5, y Nicéforo de Calisto, Hist. Eccl. VII 50. Cf. sobre este punto F. Paschoud (ed.), Zosime. Histoire nouvelle. Tome III. I $I^{\text {re }}$ partie (Livre V), París 1986, pp. 212-215, y J. M. Candau (tr.), Zósimo. Nueva historia, Madrid 1992, p. 466, n. 70 .

${ }^{27}$ Sobre este punto cf. además F. J. González Ponce, op. cit. en n. 1, pp. 31-37. 
nes del Adriático presupone el seguimiento directo del citado historiador por parte del compilador del Periplo, ya que, además de las incongruencias cronológicas apuntadas incluso por los defensores de la teoría tradicional, con ello se estarían violando las reglas propias de una obra de origen naútico. En relación con el caso concreto que nos compete expone Peretti que nuestro autor, más bien, se habría hecho eco en $\S 20$ de una opinión que, remontándose a toda una larga tradición anterior a Teopompo, era entonces moneda común entre la gente culta ${ }^{28}$, máxime cuando las bifurcaciones de los ríos y sus brazos secundarios se habían convertido en fácil expediente utilizado por poetas, geógrafos y científicos para dar respuesta satisfactoria a una serie de cuestiones cuya explicación tradicional había caído en desuso debido al progreso en el conocimiento de la ecúmene ${ }^{29}$.

Aparte de Teopompo (y de Éforo), el erudito italiano ha abordado bajo la misma óptica la cuestión de las posibles relaciones entre el contenido geográfico que leemos en el Periplo y la obra de Heródoto; y sus conclusiones, si bien referidas a otros pasajes, vienen igualmente a ratificar nuestra postura.

F. Jacoby ${ }^{30}$, representante de la teoría tradicional, consideraba el Periplo un centón conformado en el siglo IV a. C. a base de noticias geográficas tomadas indistintamente de la Periegesis de Hecateo y de las Historias de Heródoto. Como argumento pone de relieve las evidentes afinidades existentes entre el contenido del Periplo y el de los fragmentos de Hecateo, y, cuando dichos fragmentos no se han conservado, intenta subsanar el defecto mediante la comparación indirecta, recurriendo a las noticias correspondientes en Heródoto. De este modo, según él, se pone de manifiesto la estrecha vinculación entre estos dos últimos autores, que se remontarían como fuente común al geógrafo milesio: mientras que el periplógrafo habría tomado de éste únicamente la información geográfica referida a la costa, Heródoto habría incorporado el resto.

Sin embargo, según Peretti ${ }^{31}$, la teoría de Jacoby responde más bien a criterios apriorísticos, al tiempo que no se ve respaldada por un análi-

${ }^{28}$ Cf. Peretti, «Teopompo...» (en n. 2), pp. 66-70.

${ }^{29}$ La mejora del conocimiento geográfico del Asia central dio lugar a que se propusiera para el retorno de los Argonautas una ruta occidental, basada en una hidrografia semilegendaria según la cual la mayoría de los grandes ríos de Europa, de los que no se tenía conocimiento autóptico, se comunicaban entre sí. Sobre estas cuestiones cf. Peretti, "Teopompo...» (en n. 2), pp. 69-70.

${ }^{30}$ Sobre la bibliografia véase $n .11$.

${ }^{31}$ Cf. Peretti, Il Periplo di Scilace. Studio sul primo portolano del Mediterraneo, Pisa 1979, pp. 117-149. 
sis exhaustivo de los textos. El estudioso italiano vuelve a pasar revista a cada uno de los pasajes propuestos por Jacoby como ejemplos de coincidencia, en concreto el excurso líbico de Heródoto (IV 165-205) y los $\$ 107-112$ del Periplo, y en una brillante exposición llega a demostrar que más llamativas que las innegables coincidencias son, sin duda, las significativas discrepancias detectadas entre ambos autores. Por tanto, lo mismo que en el caso de las coincidencias entre Teopompo y Ps.Escílax, las que se establecen entre éste y Heródoto tampoco deben ser entendidas, según la tesis de Peretti, como fruto de una relación de dependencia directa por parte del primero, sino que constituirían los puntos básicos comúnmente aceptados por cualquier geógrafo u hombre culto entre los siglos V-IV a. C. sobre esa cuestión particular (la descripción geo-etnográfica de Libia) ${ }^{32}$. La constatación de esta realidad le lleva a proponer una explicación de la relación existente entre los tres autores citados en virtud de un esquema radicalmente opuesto al de Jacoby: según Peretti, las coincidencias detectables entre Hecateo-Heródoto y Ps.-Escílax implican, más bien al contrario, una dependencia de Heródoto y su modelo - Hecateo - con respecto al núcleo antiguo, naútico y empírico, originario del Periplo, a una tradición marinera inicial en la que el nombre del verdadero Escílax - no por casualidad mantenido por la tradición manuscrita - acapara un incuestionable protagonismo ${ }^{33}$.

Sin duda, éste es el prisma bajo el que debe ser abordada la cuestión principal del presente trabajo: la afinidad establecida entre Heródoto y el Periplo en el pasaje que nos ocupa. Después de lo dicho ¿debemos pensar en Heródoto como en el último y único responsable de las noticias por él transmitidas, considerando deudores suyos a cuantos con posterioridad coincidan con él en algún tipo de información? Probablemente no. No, al menos, cuando la naturaleza de la obra tenida por posible tributaria manifieste, como nuestro Periplo, un incuestionable origen naútico, empírico y práctico.

Al comentar el pasaje herodoteo que nos ocupa, la totalidad de los autores $^{34}$ está de acuerdo en alegar como defensa de la afirmación del historiador la propia realidad geográfica: las desembocaduras de ambos ríos están aproximadamente alineadas por el meridiano $28^{\circ}$. Sin embargo, la crítica se muestra igualmente unánime a la hora de censurar a

${ }^{32}$ Cf. Peretti, Il Periplo di Scilace... (en n. 31), pp. 123-124.

${ }^{33} \mathrm{Cf}$. Peretti, Il Periplo di Scilace... (en n. 31), pp. 121 y 148-149.

34 Cf. Bunbury, op. cit. en n. 17, vol. I, p. 233 y n. 4; Legrand (ed.), op. cit. en n. 17, Livre I, Paris 1964 [1932], p. 75; Schrader, op. cit. en n. 13, p. 147, n. 185, y How-Wells, op. cit. en n. 17, pp. 93 y 178. 
Heródoto por haber empañado tal «acierto» con el hecho de tomar como puntos de referencia en las costas de Asia Menor la ciudad de Sinope (al Norte, según él en la misma longitud que las bocas del Danubio) y el territorio de Cilicia (en el flanco mediterráneo, en su opinión frontero al delta del Nilo), a pesar de que ambos enclaves - sobre todo Sinope - se encuentran mucho más al Este ${ }^{35}$. A su vez y en estrecha relación con lo que acabamos de decir, se imputa a Heródoto un segundo «error»: el cómputo de cinco días de camino desde el uno al otro lugar supone una distancia excesivamente corta ${ }^{36}$. Se ha pensado entonces que dicho autor ha sido objeto de una falsa información, o bien ha entendido mal los datos recabados: estaría confundiendo la distancia que hay de costa a costa con la que se da realmente entre Sinope y el límite interior del territorio cilicio ${ }^{37}$. Dicho error de cálculo habría sido incorporado, sin más, por el compilador del Periplo.

El problema, no obstante, requiere volver a ser planteado. Una ligera modificación en la citada noticia de Heródoto habría arrojado resultados bien distintos en la interpretación de la misma: si en lugar de «un viajero sin bagajes» entendemos que Heródoto se está refiriendo a las etapas de relevo de un correo - posibilidad que apunta ya la crítica tradicional - parece vislumbrarse una posible reconciliación entre la inaudita información del historiador y la propia realidad ${ }^{38}$. Que la suposición puede ser correcta parece deducirse de las palabras del Ps.-Escílax, que en $\S 102$ no menciona en absoluto el avmp $\varepsilon u ̈ \zeta \omega v o \zeta$, como muy oportunamente apunta ya E. H. Bunbury. Heródoto, entonces, no habria sido mal informado, sino que habria entendido mal las noticias recibidas. De otra manera: se habría equivocado de viajero, pero no por ello hay que pensar que deje de hacer alusión a un trayecto de costa a

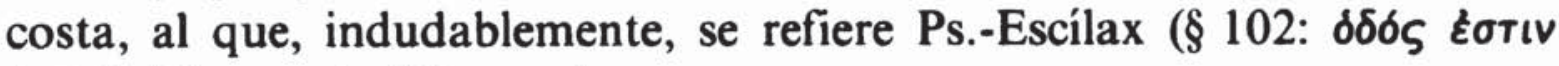

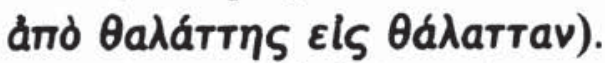

El autor del Periplo, según se deduce de lo que acabamos de decir, no es en este punto tributario de Heródoto. Al contrario, se hace eco

${ }^{35}$ Cf. How-Wells, op. cit. en n. 17, p. 178.

${ }^{36}$ En el tiempo especificado por Heródoto no pudo haberse recorrido la distancia de $560 \mathrm{~km}$. que hay desde Sinope hasta la costa cilicia, ni siquiera los $480 \mathrm{~km}$. que supone la travesía más corta de la península Anatolia, sobre todo cuando lo escabroso del relieve dificulta enormemente el viaje. El error de cálculo se pone de manifiesto si se tiene en cuenta que la marcha diaria de un avì $\varepsilon \tilde{\zeta} \zeta \omega v o \varsigma$ es, según el propio autor (IV 101, 3), de unos 200 estadios, es decir, $35,5 \mathrm{~km}$. aproximadamente.

${ }^{37}$ Cf. Schrader, op. cit. en n. 13 , p. 147 , n. 185

38 De los correos persas vuelve a hablarnos Heródoto en VIII 98, 2, y en VI 106, 1 nos dice que alguno llegó a alcanzar los $224 \mathrm{~km}$. en dos dias. En el comentario a este pasaje G. Rawlinson, Herodotus I-IV $\left(1875_{3}\right)$, expone que en sus dias un correo a caballo moderno podía recorrer $80 \mathrm{~km}$. diarios. 
igual que éste de una información de indole tradicional, de un cúmulo de noticias de dominio público al alcance de todo aquel que pudiese estar interesado por ellas, de las que, al parecer, da fe incluso con mayor exactitud que su pretendido «modelo». La tesis de Peretti y su reinvindicación de la figura del verdadero Escílax como último eslabón de la cadena de fuentes seguidas por nuestro compilador encontraría en este pasaje otra apoyatura para su defensa, ya que nadie habría podido conocer mejor que el geógrafo cario de Darío este tipo de indicaciones relacionadas con el Imperio persa en general, y en particular con el Asia Menor.

Como ya apunta E. Meyer ${ }^{39}$, todo hace pensar en la existencia de una vieja ruta imperial que atravesase la península, de un transitado camino que, aprovechando los valles de los ríos Halis y Cidno, se ofreciese como senda natural a los rápidos correos imperiales que hacian el recorrido desde Sinope a Tarso o Solos en Cilicia, vía cuya importancia en época de la compilación del Periplo está atestiguada por ser ésta la seguida por el propio Alejandro y, en parte, también por la expedición de los Diez Mil. O, si se prefiere, puede aceptarse por el contrario que el cómputo de cinco días sea simplemente erróneo, según suele ocurrir cuando el espacio es concebido unidimensional y hodológicamente, como defiende P. Janni ${ }^{40}$. Desde el punto de vista de nuestro razonamiento es indiferente inclinarse por una $u$ otra hipótesis. Pero incluso si se acepta este último supuesto la discordancia observable no tiene por qué ser achacada a Heródoto ni, mucho menos, a nuestro compilador, sino al acopio de conocimientos empíricos pertenecientes al patrimonio común de toda la colectividad del que ambos se nutren, a esas informaciones tradicionales, surgidas de la cotidiana experiencia itineraria, de la reiterada $\varepsilon \mu \pi \varepsilon$ เрía de viajeros y navegantes, que en un mundo como el antiguo son las únicas bases «científicas» posibles con las que cuenta el geógrafo para llevar a cabo la explicación «lógica» del entorno que le rodea. Es más, sólo recurriendo como argumento a la mediación de este saber colectivo y transgeneracional, que en ocasiones aflora en determi-

${ }^{39}$ Cf. E. Meyer, Geschichte des Altertums, vol. II, p. 287, ap. How Wells, op. cit. en n. 17 , p. 93.

40 De acuerdo con Janni, La mappa e il periplo. Cartografia antica e spazio odologico, Roma 1984, p. 154, esta falta de exactitud en el cálculo de la anchura de la península podría estar relacionada con la propia orografia del terreno: la proliferación en territorio anatolio de cadenas montañosas orientadas de Este a Oeste explican que los recorridos más frecuentados fuesen aquellos que lo atravesaban a lo largo, mientras que la misma circunstancia justifica la escasa proliferación de recorridos a lo ancho. Se comprende de este modo que las noticias sobre las distancias Norte-Sur fueran mucho menos abundantes y, por tanto, mucho más sospechosas de falsedad. 
nados autores y en épocas distantes traicionando incluso la propia tradición literaria, es como puede explicarse otro hecho que no ha llamado menos la atención de los críticos: el que Plinio, $\mathrm{NH}$ VI 7, en fecha tan tardía y a pesar del absoluto dominio geográfico de la región (ya Eratóstenes, ap. Estrabón II 1, calculó con exactitud la medida en 3.000 estadios), vuelva a estimar "erróneamente» la distancia entre Sinope y el mar de Chipre en 200 millas romanas (unos $295 \mathrm{~km}$.), menos aún que lo que leemos en Heródoto y el Periplo.

Igual explicación cabe proponer para el primero de los «errores»: la «incomprensible» alineación por parte del historiador y del Ps.-Escílax de los puntos desembocadura del Danubio-Sinope-costa cilicia-desembocadura del Nilo. Efectivamente, no es una observación gratuita la de los comentaristas W. W. How y J. Wells al exponer que este pasaje debe entenderse como uno de los primeros intentos de trazar «a rough parallel of longitude ${ }^{41}$ por parte de un geógrafo griego. Dicha afirmación no hace más que poner de relieve una vez más el origen empírico, cualitativo y hodológico de la noticia que comentamos. Es decir, el establecimiento por parte de Heródoto de este "proto-meridiano" jalonado en sus extremos por las desembocaduras de los dos grandes ríos no se entiende sin la existencia real de la importante ruta ya citada que uniría entre sí los puntos intermedios: Sinope y Cilicia. Tanto es así que incluso en épocas posteriores la "rigurosa» división de la tierra en $365^{\circ}$ por obra de la geografía matemática nunca se ve libre del sustrato plurisecular integrado por la experiencia cotidiana de navegantes y viajeros: los meridianos y paralelos trazados por Eratóstenes e Hiparco (y luego por Estrabón) siempre se hacen coincidir con las grandes vías que ya entonces constituían el «mapa de rutas» estándar de la ecúmene ${ }^{42}$. $\mathrm{Si}$ además se recuerda que el geógrafo de Halicarnaso, como dijimos en su momento (cf. lo expuesto en n. 17), está haciendo gala en este pasaje de otro de los rasgos comunes en la concepción geográfica de los Griegos desde sus más remotos inicios, la simetría, todo queda explicado.

Pasemos ahora a la segunda cuestión, sin duda la que más nos interesa resolver: ¿las razones que nos impiden observar en el lugar que co-

${ }^{41}$ Cf. How-Wells, op. cit. en n. 17, pp. 178 y 435.

${ }^{42} \mathrm{Cf}$. sobre este punto F. Prontera, "Géographie et mythes dans l'isolario des Grecs", en M. Pelletier (ed.), Géographie du Monde au Moyen Âge et à la Renaissance, París 1989, pp. 169-179; "L'estremo Occidente nella concezione geografica dei Greci», Atti del Ventinovesimo Convegno di Studi sulla Magna Grecia, Tarento 1990, pp. 55-82, y «Periploi: sulla tradizione della geografia nautica presso i greci», L'uomo e il mare nella civiltà occidentale: da Ulisse a Cristoforo Colombo, Génova 1992, pp. 26-44. 
mentamos un préstamo directo de Heródoto deben al mismo tiempo

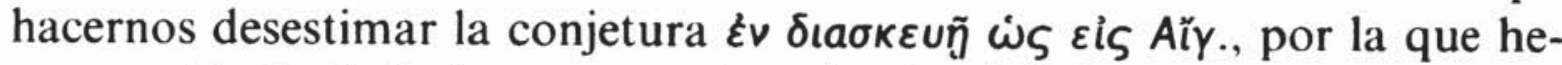
mos venido inclinándonos como la más plausible?

A tal conclusión se habría debido llegar desde los planteamientos de la teoría tradicional, cuyos representantes se limitan a ver en el Periplo un collage de noticias geográficas tomadas por su anónimo compositor directamente de las obras de una serie de autores precedentes que le sirvieron de modelos. Si algunos de los defensores de esta teoría tradicional son al mismo tiempo partidarios de la citada conjetura (Gail, Fabricius, Müller), ello se debe a que dichos investigadores no han prestado, intencionada o desintencionadamente, la debida atención a esa grave incongruencia en el contenido geográfico que encierra el pasaje, según hemos venido apuntando a lo largo de todo el trabajo.

Sin embargo, si, como hemos procedido en las lineas precedentes, se prescinde de los planteamientos tradicionales y se da por buena la renovada visión de los hechos que nos brinda Peretti, parece vislumbrarse con cierta claridad una posible solución del problema planteado. La viabilidad de la conjetura propuesta, por tanto, no está garantizada por su «evidente» e «innegable» paralelismo con Heródoto, como hemos intentado demostrar. La incongruencia del resto del pasaje $(\$ 20)$ con el esquema geográfico de Heródoto subraya la debilidad de la que suelen pecar este tipo de argumentos esgrimidos por la crítica tradicional. Más bien al contrario, dicha conjetura puede - y debe - defenderse a pesar de la ya reiteradamente aludida desvinculación directa de nuestro Periplo con respecto a las Historias, desvinculación que, en cambio, se ve subsanada por el hecho de que ambos autores reciben el fruto de una misma tradición.

El escueto $\S 20$, en definitiva, se convierte según nuestra reflexión en uno de los pasajes que con mayor claridad permite comprobar la validez de los renovados esquemas propuestos por Peretti en relación con las fuentes del Periplo, su origen y su naturaleza, conclusión a la que nos han conducido, paradójicamente, sus propias insuficiencias textuales. El loable estudioso italiano no supo sacar de él, quizá, todo el partido.

\section{F. J. González Ponce}

